\title{
Sleep Disorders Impair Attaining Ideal Cardiovascular Health
}

\author{
Camila Christina Santos de Oliveira, ${ }^{\circledR}$ Sergio Tufik, Monica Levy Andersen \\ Universidade Federal de São Paulo (UNIFESP) - Psicobiologia, São Paulo, SP - Brazil
}

In the recent article "Ideal Cardiovascular Health and Job Strain: A Cross-Sectional Study from the Amazon Basin", by Muniz et al., ${ }^{1}$ the authors proposed that cardiovascular health (CV) is influenced by the workplace conditions. The study involved 478 employees, which had wide access to health information, from a University in the Amazon Basin, Brazil. Researchers used a validated version of the Job Demand Control Model (JDC model) $)^{2}$ questionnaire to assess work stress. The study is an innovative one, since it is the first one to explore this hypothesis in the Amazon Basin. The authors found a high prevalence of poor $\mathrm{CV}$, which was mainly associated with a poor diet and obesity, ${ }^{1}$ suggesting that participants with high job strain are more likely to have eating disorders, resulting in weight gain.

Weight gain and hormonal alterations have been observed in patients with sleep disturbances, such as obstructive

\section{Keywords}

Sleep/physiopathology; Sleep Wake Disorders/ physiopathology; Cardiovascular Diseases; Ocupational Stress

Mailing Address: Monica Levy Andersen •

UNIFESP - Psicobiologia - Rua Napoleão de Barros, 925. Postal Code 04021-001, São Paulo, SP - Brazil

E-mail: ml.andersen12@gmail.com

Manuscript received January 28, 2019, revised manuscript April 10, 2019, accepted April 10, 2019 sleep apnea. Obstructive sleep apnea is a very prevalent sleep disorder that leads to the development of metabolic syndrome, cardiovascular outcomes and contributes to systemic inflammation. ${ }^{3}$

According to Genta et al., ${ }^{4}$ sleep disorders, in association with obesity, also cause cognitive deficit, difficulty in concentration and irritability. It is important to highlight that the effects of sleep disorders are not restricted to the nocturnal period, but may extend throughout the day and, consequently, decrease the quality of life of the affected individuals.

Muniz et al. ${ }^{1}$ proposed to fight obesity, thereby reducing poor CV outcomes, through strategies to develop healthy behaviors such as physical activity projects, educational campaigns and making a low-fat diet available in the campus restaurants. We would like to highlight the fact that the inclusion of sleep awareness campaigns could also bring benefits to the employee's health. Sleep hygiene habits are critical to maintaining a healthy lifestyle. One of the most important elements of these habits is sleep duration, which should be adequate without excess or deprivation. The National Sleep Foundation ${ }^{5}$ proposes that simple changes be made and applied regarding the daily sleep hygiene routine. In addition, the investigation of sleep disorders by health professionals can have a great impact on life expectancy and on improving cardiovascular health.

DOI: $10.5935 / a b c .20190110$

\section{Referencias}

1. Muniz DD, Siqueira KS, Cornell CT, Fernandes-Silva MM, Muniz PT, Silvestre OM. Ideal cardiovascular health and job strain: a cross-sectional study from the Amazon basin. Arq Bras Cardiol. 2019; 112(3):260-8.

2. Mulder P. Job demand control model by Robert Karasek. [ Citado em 2019 jan 11]. Disponível em: https://www.toolshero.com/stress-management/ job-demand-control-model/

3. Lavie L, Lavie P. Molecular mechanisms of cardiovascular disease in OSAHS: the Oxidative Stress Link. Eur Respir J. 2009;33(6):1467-84.
4. Genta PR. Hcor Instituição Beneficiente Síria [homepage na internet]. Como Previnir os Distúrbios do Sono. [Citado e 2019 jan 11]. Disponível em: https://www.hcor.com.br/materia/como-prevenir-osdisturbios-do-sono/

5. National Sleep Foundation. Higiene do Sono. [Homepage]. [Cited in 2019 jan 11] Disponível em: https://www.sleepfoundation.org/sleep-topics/ sleep-hygiene 


\section{Reply}

We appreciate the interest in our study. We agree with our readers that sleeping disorders may play a role in the association between job strain and cardiovascular health. Sleep apnea has a prevalence of 35\% among those with overweight. ${ }^{1}$ In our sample, more than $65 \%$ had $\mathrm{BMI}>25 \mathrm{~kg} / \mathrm{m}^{2}$, suggesting a high prevalence of sleep apnea and probably a high influence in job stress. Although sleep apnea screening using questionnaires or polysomnography was not performed in our study, we asked the participants whether they had sleeping disturbances in the previous weeks due to any concerns at the workplace. We found that those with high job strain were more likely to answer "yes" to this question than other participants (40\% vs $21 \%$, $p<0.001$ ), suggesting that a low sleep quality was more prevalent among those with high job strain. Therefore, future studies should evaluate whether sleep disturbances can explain the association between job strain and cardiovascular health. In accordance with our readers, we propose a strategy to promote a healthy lifestyle that would encompass a sleep awareness campaign, including promotion of sleep hygiene and also questionnaires to screen for sleep apnea. In addition, programs to control obesity would help to improve sleep quality, because it has been proved to reduce the apnea-hypopnea index in subjects with sleep apnea. ${ }^{2}$ In conclusion, strategies that include sleep awareness may help improve the impact on cardiovascular health.

Davi Dantas Muniz Miguel Morita Fernandes-Silva Odilson Marcos Silvestre

\section{References}

1. Romero-Corral A, Caples SM, Lopez-Jimenez F, Somers VK. Interactions between obesity and obstructive sleep apnea: implications for treatment. Chest. 2010;137(3):711-9

2. Smith PL, Gold AR, Meyers DA, Haponik EF, Bleecker ER. Weight loss in mildly to moderately obese patients with obstructive sleep apnea. Ann Intern Med. 1985;103(6 Part 1):850-5. 